\title{
INDAGANDO OS "MODOS DE VER" DA POLÍTICA URBANA: O PROBLEMA PÚBLICO DO CRESCIMENTO URBANO NA CIDADE DO RIO DE JANEIRO
}

\section{Ana Brasil Machado*}

Pontifícia Universidade Católica do Rio de Janeiro

\section{Leticia Parente Ribeiro**}

Universidade Federal do Rio de Janeiro

Resumo: Ao longo dos anos 2000, o problema do crescimento urbano passou por um processo de redefinição cognitiva no âmbito das políticas públicas da cidade do Rio de Janeiro. Tal mudança fez emergir um novo regime de visibilidade, um novo modo de ver, imaginar e definir este problema. A partir da análise de artigos da Coleção Estudos Cariocas, publicada pelo Instituto Pereira Passos, bem como de fontes hemerográficas, foi possível constatar que o problema do crescimento urbano, antes concebido em termos do crescimento populacional nas favelas, passa a descrever a expansão das áreas de favelas sobre áreas de proteção ambiental. Tal mudança realçou o caráter relacional do espaço e a natureza descontínua da cidade, além de chamar a atenção para a necessidade de elaboração de políticas que considerem os limites e as "zonas de contato" como elementos constituintes do espaço urbano.

Palavras-chave: Crescimento urbano. Problema público. Regime de visibilidade. Favelas. Rio de Janeiro.

\section{INQUIRING THE "WAYS OF SEEING" OF URBAN POLICIES: THE PUBLIC PROBLEM OF URBAN GROWTH IN THE CITY OF RIO DE JANEIRO}

Abstract: Throughout the 2000s, the problem of urban growth underwent a process of cognitive redefinition within the scope of public policies of the city of Rio de Janeiro. Such a change has given rise to a new regime of visibility, a new way of seeing, imagining, and defining this problem. From the analysis of works published in the Estudos Cariocas collection, from the Pereira Passos Research Institute, as well as from hemerographic sources, it was possible to verify that the problem of urban growth, previously conceived in terms of population growth in the favelas, went on to describe the expansion of favela areas over areas of environmental protection. Such a change emphasized the relational character of space and the discontinuous nature of the city, drawing attention to the need for policy making that considers boundaries and "contact zones" as constituent elements of urban space.

Keywords: Urban growth. Public problem. Visibility regime. Favelas. Rio de Janeiro.

\section{INVESTIGANDO LAS "FORMAS DE VER" DE LA POLÍTICA URBANA: EL PROBLEMA PÚBLICO DEL CRECIMIENTO URBANO EN LA CIUDAD DE RÍO DE JANEIRO}

Rsumem: A lo largo de la década de 2000, el problema del crecimiento urbano experimentó un proceso de redefinición cognitiva en el marco de las políticas públicas en la ciudad de Río de Janeiro. Tal cambio ha dado lugar a un nuevo régimen de visibilidad, una nueva forma de ver, imaginar y definir este problema. Del análisis de artículos de la Colección de Estudios Cariocas, publicado por el Instituto Pereira Passos, así como de fuentes hemerográficas, fue posible verificar que el problema del crecimiento urbano, previamente concebido en términos de crecimiento de la población en las favelas, llegó a describir la expansión de las áreas de favelas sobre áreas de protección ambiental. Este cambio ha resaltado el carácter relacional del espacio y la naturaleza discontinua de la ciudad, además de llamar la atención sobre la necesidad de desarrollar políticas que consideren los límites y las "zonas de contacto" como elementos constitutivos del espacio urbano. Palabras clave: Crecimiento urbano. Problema público. Régimen de visibilidad. Favelas. Rio de Janeiro. 
Introdução

Ao longo do século $\mathrm{XX}$, a questão do crescimento extensivo das cidades participou de maneira importante das discussões sobre o planejamento urbano' ${ }^{1}$. 0 debate sobre seus efeitos se tornou mais relevante a partir do final da Segunda Guerra Mundial, quando o padrão de suburbanização se desenvolveu significativamente nos Estados Unidos. Mas foi nas décadas de 1960 e 1970, com a crise urbana e econômica e com a emergência do movimento ambientalista, que esta preocupação se tornou mais evidente e a expansão urbana passou a estar associada a um amplo leque de custos ambientais e sociais ${ }^{2}$.

São inúmeros os exemplos de cidades que adotam políticas públicas voltadas para a gestão do crescimento extensivo e a proteção de espaços livres. Estas políticas se alinham às críticas ao modelo de cidade não densa, associado a maiores gastos energéticos e maiores demandas de infraestrutura, ao aumento da duração dos deslocamentos diários e da poluição, e à diminuição de áreas livres e de espaços públicos. No entanto, não foi apenas o crescimento nos limites externos das cidades que esteve em jogo, mas também o "crescimento interno", ou seja, a expansão de determinadas áreas ou classes de uso internas às cidades.

$\mathrm{Na}$ cidade do Rio de Janeiro, ao longo dos anos 2000, o projeto denominado "ecolimites" foi mobilizado em diversos momentos (MACHADO, 2017, 2018a). O projeto não visava gerir o perímetro urbano da cidade, mas tinha como objetivo declarado conter o crescimento das favelas sobre as áreas verdes da cidade. De acordo com Ícaro Moreno, então presidente da Empresa de Obras Públicas do Estado do Rio de Janeiro (EMOP), "a ideia é proteger a comunidade de um lado e a Mata Atlântica do outro. Fica mais fácil a fiscalização e ajuda a dimensionar as ações nas comunidades" ( $O$ Globo, 28/3/2009).

$\mathrm{Na}$ versão apresentada em 2009, os ecolimites deveriam ser instalados em onze favelas localizadas na Área de Planejamento 2, Zona Sul do Rio de Janeiro ${ }^{3}$. Assumiriam a forma de muros de aproximadamente três metros de altura e deveriam ser construídos ao longo das linhas de contato entre as favelas e as áreas a serem preservadas. Estes muros substituiriam os antigos marcos de concreto e cabos de aço, também chamados de ecolimites, já instalados em 33 favelas \Ver a este respeito Capel (2002), Frankhauser (1994), Hall (2013), Murdoch (2006),
Robic (2003 e 2006), Pendall, Martin e Fulton (2002) e George (1983).
Ver, por exemplo, Bengston, Fletcher e Nelson (2004), Villamizar-Duarte e Sánchez
(2012), Bengston e Youn (2006), Barnier e Tucoulet (1999), Costa (1999) e Rosales
e Sanchéz (2011).
Santa Marta, Rocinha, Chapéu Mangueira, Benjamin Constant, Chácara do Céu,
Parque da Cidade, Morro dos Cabritos, Tabajaras, Pavão-Pavãozinho, Cantagalo e
Vidigal. a partir de 2001, na gestão do prefeito Cesar Maia. Em 2004, Luiz Paulo Conde, então secretário estadual e vice-governador na gestão da governadora Rosinha Garotinho, já havia proposto a construção de muros em favelas cariocas selecionadas. No entanto, o projeto do arquiteto foi "rechaçado pela mídia e pela opinião pública e, por isso, não foi levado adiante" (PEDROSO, 2009: 19).

O objetivo de conter a expansão das favelas sobre as áreas verdes, que norteava o projeto de 2009 , foi questionado, bem como o modelo de delimitação, amplamente relacionado à intenção de consolidar a segregação socioespacial na cidade. A implantação dos ecolimites foi tema de um intenso debate público. Finalmente, o muro foi construído apenas na favela Santa Marta, e na Rocinha o projeto foi substituído por um parque linear, denominado Parque Ecológico da Rocinha. Entretanto, a despeito de sua exígua materialização, o ecolimite assumiu distintos significados e estabeleceu relações espaciais entre formalidade e informalidade, natureza e artifício, áreas com o crescimento a ser contido e áreas de preservação. Funcionou como um objeto-síntese, capaz de concentrar diferentes questões pertinentes à cidade do Rio de Janeiro (MACHADO, 2017).

Uma das questões a que o ecolimite esteve associado foi a do crescimento horizontal, notadamente de favelas sobre áreas de proteção ambiental. Entendidos como dispositivos de regulação de interfaces, os ecolimites atuaram como descontinuidades físicas, mediando a relação entre categorias mais abstratas, tais como a "cidade" e a "natureza". Dada a grande repercussão do debate público sobre o projeto, inclusive no âmbito das discussões que, já na década de 2010, culminaram com a aprovação do novo Plano Diretor da cidade, partimos da hipótese de que os ecolimites fazem parte de um quadro mais geral, em que a própria concepção do crescimento urbano na cidade do Rio de Janeiro se encontrava em um processo de redefinição.

Dessa maneira, o objetivo deste artigo é descrever um momento particular da redefinição do problema do crescimento urbano na cidade do Rio de Janeiro do qual os ecolimites fazem parte. Esta redefinição pode ser lida a partir da análise da construção de um novo regime de visibilidade, ou seja, um novo modo de ver e, portanto, de conceber e de atuar sobre o crescimento da cidade.

No caso da cidade do Rio de Janeiro, ao longo dos anos 2000, o crescimento urbano e, mais especificamente, o crescimento urbano extensivo (ou seja, a expansão horizontal, que não se confunde com o crescimento demográfico, com o crescimento vertical e tampouco com o adensamento) se apresentaram como um problema na esfera pública e, concomitantemente, 
passaram por um processo de institucionalização no âmbito das políticas públicas municipais (com a proposição de novos instrumentos e novas normas para enfrentá-los). Não se trata aqui de reconstruir a gênese deste problema, mas de analisá-lo em um momento de redefinição, no âmbito das transformações ocorridas na política urbana do Rio de Janeiro.

\section{Vendo o problema público como uma cidade}

Como sugere Daniel Cefai (2018), um problema público, como aquele que nos interessa, deve ser analisado em sua trajetória, ou seja, atentando para as mudanças cognitivas e normativas envolvidas em seu processo de publicização. Estas mudanças resultam das atividades dos atores envolvidos, os quais procuram determinar, no intuito de "controlá-las, suas condições de partida, as fases de seu desenvolvimento e suas consequências" (CEFAI, 2018: 1). As atividades significativas na trajetória de um problema público são aquelas de investigação (como, por exemplo, procurar estabelecer as variáveis e os meios que permitem defini-lo, mensurá-lo, acompanhar sua evolução), de experimentação (como formular propostas, testá-las, compará-las) e de discussão pública (que implicam identificar quem participa legitimamente do debate e em que espaços ele pode ocorrer). Uma das características centrais das atividades envolvidas no processo de publicização é o fato de que elas são mediadas por objetos:

As configurações dos objetos - que podem ser caixas de ferramentas, regras de direito ou organogramas de organizações, arranjos espaciais ou agendas temporais, equações formais, ideias normativas ou seres divinos - não são inertes. Elas constituem um "ambiente operatório", que é o da definição e do controle das situações problemáticas; e elas contribuem para o ordenamento de formas de poder e de mudança, de cooperação e de comunicação. (Cefai, 2018: 23)

É também em função das condições deste "ambiente operatório" que uma situação problemática se torna pública, no sentido de se tornar visível. No caso dos "problemas urbanos", sua visibilidade é comumente articulada por intermédio das normas e dos instrumentos que compõem a política urbana. Como discutido amplamente por Mariana Valverde (2005, 2011), o planejamento urbano (e, mais especificamente, a legislação urbana) constitui um modo específico de governo, o qual supõe um modo de ver seu(s) objeto(s). Para Valverde $(2005,2011)$, "ver como uma cidade" (seeing like a city) implica, predominantemente, governar "usos" e não "pessoas" (ou, ainda, governar pessoas e coisas por meio do governo dos "usos"). Neste sentido, a categoria de "uso do solo" constitui uma tecnologia legal própria do planejamento e, mais especificamente, do planejamento urbano, empregada no intuito de orientar e de controlar a organização do espaço urbano.

A característica fundamental da categoria "uso do solo" é que ela opera a partir de um conjunto articulado de unidades espaciais justapostas. As "classes (discretas) de uso do solo" são, portanto, entendidas como "recipientes" (containers) espaciais dotados de atributos próprios e de limites externos, ou seja, como regiões delimitadas no espaço (BLOMLEY, 2016). No âmbito da política urbana, a delimitação das classes de uso do solo é, portanto, constitutiva de sua definição legal.

Os limites possuem significado. Eles significam, diferenciam, unificam os interiores dos espaços que demarcam. [...] E a forma que este significado geralmente assume - o significado que os atores sociais conferem às linhas e espaços - é o sentido legal. Seu significado decorre, portanto, da inscrição oficial de categorias legais, ou da projeção de imagens e narrativas legais no mundo material das coisas. (BLOMLEY et al., 2001: xviii, grifos no original)

Se adotarmos uma perspectiva relacional do espaço (MURDOCH, 2006), segundo a qual todas as entidades sociais devem ser compreendidas a partir de suas interações, poderíamos questionar a própria estabilidade destas "classes de área" legalmente definidas. Estas passariam a ser compreendidas "não [como] unidades territoriais, mas como composições dinâmicas [...], construídas a partir da espacialidade do fluxo, da justaposição, da porosidade e da conectividade relacional" (BRAVERMAN et al., 2014). Esta abordagem sugere novas formas de compreender os espaços legais (como o são aqueles definidos a partir da categoria "uso do solo"), indo além da análise das unidades espaciais estáveis e de seus elementos constitutivos (como, por exemplo, os limites) para nos voltarmos para os próprios processos de delimitação (bordering), nos quais os limites são entendidos não como lugares fixos e inertes, mas como práticas negociadas, contingentes, ad hoc, intermediadas pelas normas, pela legislação e pelos instrumentos de política pública.

Ora, delimitar espaços legais constitui uma das formas privilegiadas da política urbana de definir e de agir sobre os problemas públicos e, consequentemente, de Ihes conferir visibilidade. Ao enfatizarmos os processos de delimitação dos "espaços legais", 
devemos atentar, portanto, não para a visibilidade per se dos problemas públicos, mas para as transformações nos modos através dos quais eles se tornam visíveis, os quais, por sua vez, alteram, ao longo do tempo, sua própria definição. Para tanto, é útil empregarmos a noção de regime de visibilidade, tal como proposta por Gomes (2013). Para o autor, os regimes de visibilidade constituem os

protocolos que estabelecem socialmente aquilo que deve ser visto, as condições e os valores que devem ser julgados [...]. [eles] nos informam sobre o que deve ser visível, como aquilo que é visto deve ser entendido e, simultaneamente, o que não merece ser visto. (GOMES, 2013: 51-52)

Ainda de acordo com Gomes (2013), os regimes de visibilidade são modulados pela espacialidade e se constituem pela interdependência entre três elementos, a saber: pontos de vista, composições e exposições. Cada regime de visibilidade é definido por um ou mais pontos de vista (lugares e instrumentos privilegiados de onde e a partir dos quais se vê o fenômeno ou o problema), uma composição (uma forma de associar as coisas figuradas em um mesmo enquadramento, uma forma de configurá-las) e suas condições de exposição (que incluem os lugares para ver o fenômeno ou o problema, bem como as audiências visadas).

A noção de regime de visibilidade, bem como os conceitos a ela relacionados, serão fundamentais para compreendermos o problema público do crescimento urbano, tal como ele foi redefinido ao longo dos anos 2000 na cidade do Rio de Janeiro a partir de mudanças cognitivas e normativas ocorridas no âmbito da política urbana municipal. É uma das hipóteses centrais deste artigo que o regime de visibilidade emergente acerca do problema do crescimento envolveu processos de delimitação no âmbito do ordenamento do espaço urbano carioca, mobilizando ativamente as categorias de limites e de interfaces e, concomitantemente, redefinindo a própria espacialidade deste problema.

\section{Um "banco de dados" das favelas cariocas}

A introdução de políticas de urbanização das favelas a partir da década de 1980 na cidade do Rio de Janeiro foi acompanhada não apenas por uma transformação em seu conceito jurídico, como discutido extensamente por Rafael Gonçalves (2013), mas também, e para os objetivos deste artigo, por uma ampla reorganização dos modos de conhecimento relativos a estas entidades geográficas, sobretudo no âmbito de alguns órgãos do governo municipal.

Em 1981, foi elaborado o Cadastro de Favelas da Cidade do Rio de Janeiro, um banco de dados pioneiro contendo informações qualitativas e quantitativas sobre as favelas cariocas, muitas delas obtidas por meio de entrevistas realizadas com antigos residentes e líderes comunitários. Ainda no âmbito do Cadastro, foram realizadas as primeiras delimitações das favelas da cidade sobre as plantas cadastrais de 1975, em escala 1:2.000, as quais foram elaboradas a partir do voo aerofotogramétrico realizado no mesmo ano. Com o auxílio de dados obtidos em pesquisas de campo, foram gerados mapas individualizados das favelas (CAVALLIERI; LOPES, Estudos Cariocas, 2006).

Em 1990, entretanto, "a partir da compreensão de que os processos de ocupação dos assentamentos de baixa renda demandavam um sistema próprio e mais complexo de acompanhamento e avaliação", o governo municipal, através do Iplanrio ${ }^{4}$, criou o Sabren (Sistema de Assentamentos de Baixa Renda), que incorporou o antigo Cadastro de Favelas (Cavallieri; Vial; Lopes, Estudo Cariocas, 2007). O Sistema passou a integrar dados oriundos de fontes diversas, como Censos Demográficos do IBGE e registros administrativos provenientes especialmente da Secretaria Municipal de Habitação e Cidadania (SMHC), da Secretaria Municipal de Urbanismo (SMU) e da Defesa Civil.

Uma das mais importantes inovações introduzidas pelo Cadastro consistiu na definição das favelas como unidades espaciais delimitadas, inscritas graficamente nas plantas cadastrais da cidade como áreas, com perímetros lineares e mensuráveis. Com a implantação do Sabren, as informações conservadas nos mapas em papel que constituíam o antigo Cadastro passaram a compor um sistema georreferenciado que associa, ainda hoje, aspectos físicos e históricos da ocupação das favelas, equipamentos urbanos e comunitários, dados acerca da regularização urbanística e fundiária, informações cartográficas (aerofotos, mapas e restituições) e de infraestrutura (CAVALLIERI; VIAL; LOPES, Estudos Cariocas, 2007). "Este sistema informatizado [...] permite ver as favelas e outros assentamentos sobre as restituições cartográficas ou sobre as ortofotos digitais que contêm outros elementos urbanos e naturais restituídos" (Cavallieri; Vial; Lopes, Estudos Cariocas, 2007: 4, grifos nossos).

A progressiva reestruturação dos sistemas de informações concernentes às favelas cariocas participa, então, como mais um elemento da evolução do "problema público" ora em tela. Em primeiro lugar, 
observa-se o destaque conferido à dinâmica de certas unidades geográficas: as favelas. Outra importante transformação diz respeito aos meios de visualização e mensuração do crescimento urbano. O enfoque demográfico, baseado em medidas do crescimento populacional, vai sendo substituído por uma ênfase no crescimento horizontal, calculado a partir das alterações do perímetro de certas áreas da cidade. Finalmente, a própria espacialidade do problema do crescimento urbano é redefinida, e ganham relevo as unidades de área envolvidas, seus limites e suas interfaces.

Duas fontes são particularmente pertinentes para se observar a transformação cognitiva pela qual passa o problema do crescimento urbano na cidade do Rio de Janeiro nas primeiras décadas do século XXI. A primeira corresponde à coleção Estudos Cariocas, criada em 2001, no âmbito do Instituto Pereira Passos (IPP), com o objetivo de divulgar trabalhos de caráter técnico ou científico e subsidiar as políticas públicas para a cidade do Rio de Janeiro. Os estudos nela publicados são produzidos por colabores internos e externos à Prefeitura e aprovados pelo Conselho Editorial da revista ${ }^{5}$. Entre 2001 e 2012, a coleção publicou dez estudos específicos sobre o crescimento das favelas a partir de dados diversos disponíveis na base do Sabren. Entre 2012 e 2018 nenhum estudo sobre o tema foi publicado na coleção. A segunda fonte corresponde ao jornal $O$ Globo, em particular às matérias publicadas na editoria Rio. Entre os anos de 2001 e 2017, foram selecionadas dez reportagens sobre o crescimento das favelas no acervo do jornal. Passemos então a uma discussão baseada no cotejo entre os conteúdos disponíveis nos acervos dessas duas fontes.

Metamorfoses do crescimento urbano: do acréscimo demográfico à expansão horizontal das favelas

Em maio de 2001, o jornal O Globo publica matéria intitulada "Cidade incha pelas favelas: estudo revela que Rio voltou a crescer e ganhou uma Petrópolis entre 96 e 2000". 0 estudo ao qual a matéria se refere havia sido elaborado pelo IPP a partir da comparação dos dados da Contagem da População (1996) e do Censo Demográfico (2000), ambos realizados pelo IBGE (O Globo, 29 de maio de 2001). Ainda de acordo com a matéria, o estudo do IPP atribuía o crescimento demográfico da cidade na segunda metade da década de 1990 ao crescimento das favelas, especialmente aquelas situadas na baixada de Jacarepaguá, e também ao crescimento dos loteamentos irregulares, sobretudo em bairros periféricos da Zona Oeste. Duas imagens acompanham a reportagem (Figura 1): uma vista aérea da favela Rio das Pedras (com a Lagoa da

Figura 1 - Dois pontos de vista do crescimento das favelas no Rio.
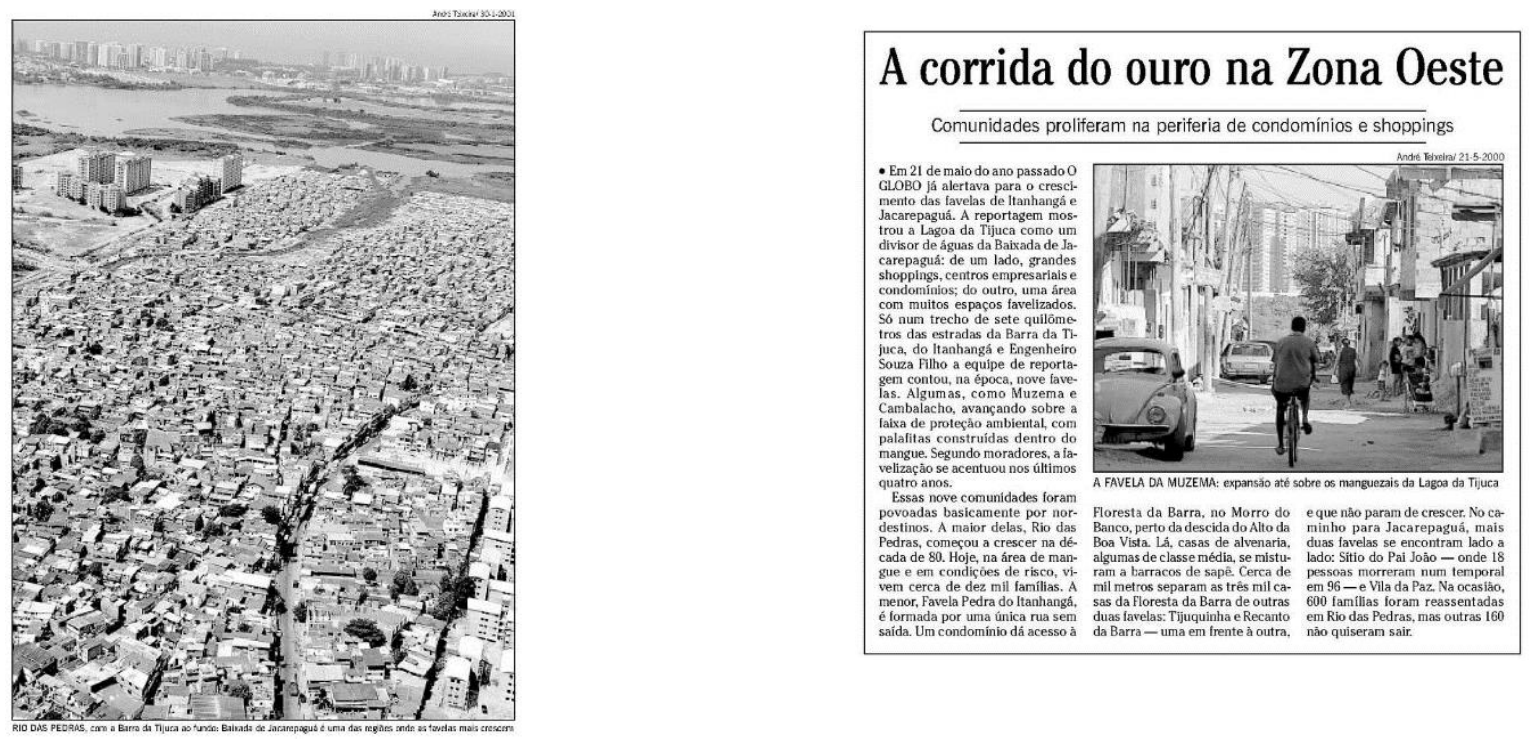

Fonte: O Globo, 29/5/2001. 
Tijuca e a Barra da Tijuca ao fundo) e uma foto de uma rua na favela da Muzema que, segundo a reportagem, "avança sobre a faixa de proteção ambiental".

Em fevereiro de 2002, o IPP publica, na coleção Estudos Cariocas, o trabalho intitulado: "Evolução da população de favelas na cidade do Rio de Janeiro: uma reflexão sobre os dados mais recentes" (Cezar, Estudos Cariocas, 2002). Embora o foco do estudo seja o crescimento demográfico, o estudo já faz menção ao chamado "crescimento horizontal" das favelas (especialmente da Zona Oeste da cidade) e sua interface com as áreas de proteção ambiental. 0 estudo combina distintas aferições do fenômeno do crescimento das favelas, diferenciando áreas nas quais há predominância de uma ou outra modalidade (crescimento demográfico, adensamento, expansão horizontal, verticalização, novos assentamentos).
Ao contrário do que aconteceu na Tijuca e em Vila Isabel, as favelas da Zona Sul continuaram se expandindo na década de 90 . Uma análise de nosso cadastro (SABREN) revela que ocorreu aqui um adensamento das favelas antigas, mais do que expansão horizontal ou novos assentamentos. [...] Entre os dois censos, o Rio ganhou 210 mil novos moradores em aglomerados subnormais ${ }^{6}$. Desses, uma terça parte se instalou nas regiões da Barra da Tijuca e Jacarepaguá (que tem apenas 12\% da população total). 0 cadastro de favelas indica que se combinouali o crescimento horizontal e vertical das favelas antigas (com destaque para o Rio das Pedras) com o surgimento de novas comunidades, especialmente à custa de áreas de preservação ambiental. [...] 0 ritmo foi um pouco mais lento que na região de Jacarepaguá, mas a Zona Oeste cresceu 2,1\% ao ano, em média, no período analisado. As taxas de crescimento mais elevadas, de até $12,8 \%$ ao ano, ocorreram nos setores subnormais das zonas periféricas, como Guaratiba, escassamente povoadas até a década de 80 . (CEZAR, Estudos Cariocas, 2002: 6-7, grifos nossos)

Figura 2 - Uma composição em três planos para o crescimento urbano.

\section{Barracos em expansão}

Estudo prevê que, em 2010, cidade terá 1,3 milhão de pessoas morando em favelas

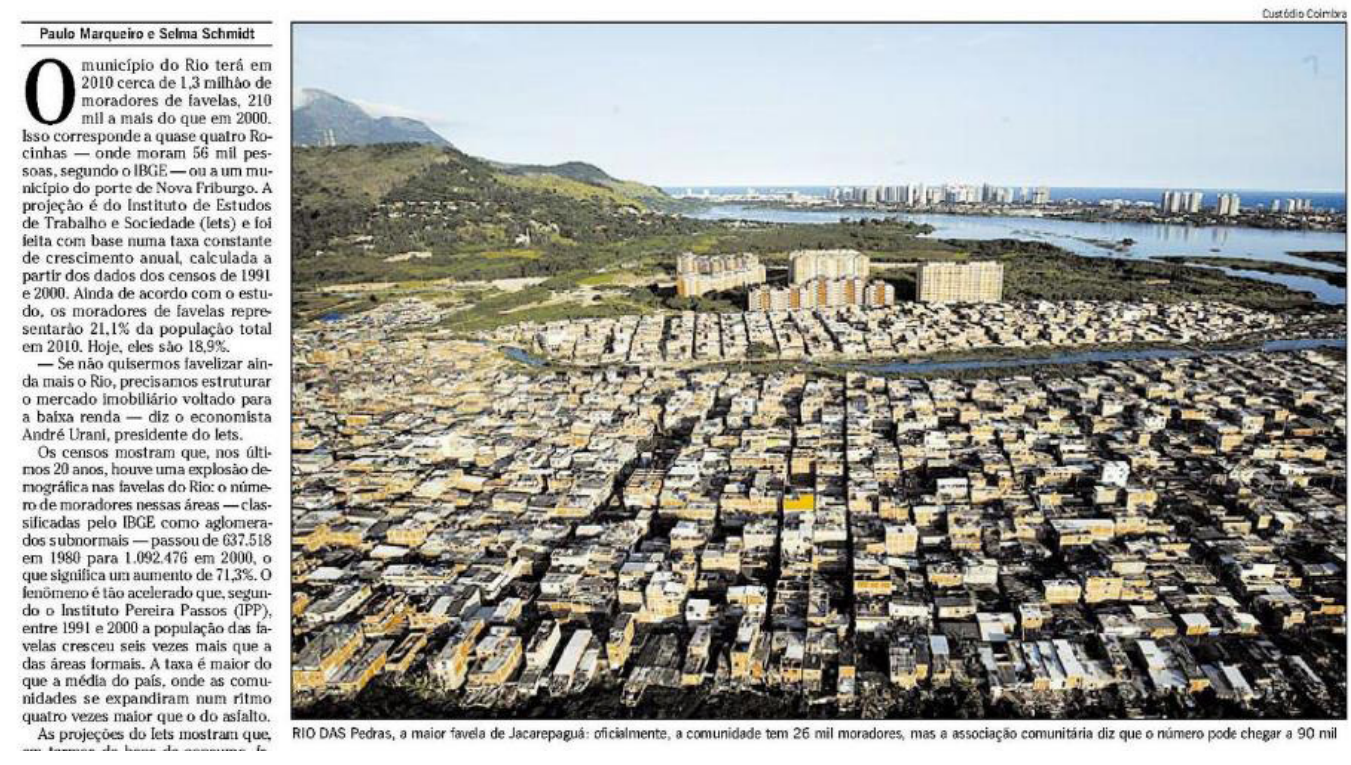

Fonte: 0 Globo, 16/5/2004. 
Em maio de 2004, O Globo publica a matéria "Barracos em expansão". A imagem que acompanha a reportagem (Figura 2) mostra, novamente, uma composição em três planos, tomada a partir de um ponto de vista aéreo, justapondo a favela de Rio das Pedras, a Lagoa da Tijuca e a Barra da Tijuca, construindo assim uma espécie de paradigma visual do fenômeno do crescimento da cidade. A reportagem lança mão ainda de um recurso analógico por meio do qual o volume total de crescimento das favelas é comparado ao tamanho demográfico de outras unidades geográficas, no caso, a favela da Rocinha e o município de Nova Friburgo, na região serrana do estado (O Globo, 16 de maio de 2004).

Em junho de 2004, é publicado, na coleção Estudos Cariocas, o trabalho: "Nota técnica sobre o crescimento da população favelada entre 1991 e 2000 na cidade do Rio de Janeiro", de autoria do então diretor de Informações Geográficas do Instituto (e presidente do mesmo Instituto por duas gestões), Sérgio Besserman Vianna. O estudo compara as taxas de crescimento de dois grandes conjuntos socioespaciais, a "favela" e a "não favela", e conclui pela existência de padrões diferenciados de crescimento demográfico (considerando o crescimento vegetativo, a migração e as taxas de fecundidade) para cada um deles (Besserman, Estudos Cariocas, 2004: 2).

Em janeiro de 2005, um novo estudo é publicado na mesma coleção: "O momento 2000 do programa FavelaBairro: avaliação com base nos censos 1991 e 2000". A base de dados consultada é a mesma do estudo anterior, isto é, os censos demográficos realizados pelo IBGE. Contudo, observa-se outra variável, a saber, o número de domicílios:

O universo de comparação compreendeu 34 favelas cujas obras de urbanização foram consideradas pela coordenação do Programa como concluídas em junho de 2000, época da coleta de campo do Censo 2000. [...] Tais favelas atenderam também ao critério de serem comparáveis com os polígonos censitários definidos pelo IBGE em 1991. Isso porque em alguns casos, embora tivessem o mesmo nome, os polígonos de 1991 eram muito diferentes daqueles definidos em 2000. No período em questão, nessas 34 favelas, o número de domicílios cresceu cerca de $17 \%$, enquanto o número de moradores cresceu $5,6 \%$. Isso reproduz uma tendência geral da população carioca de diminuição do tamanho das famílias, o que é corroborado pela redução do índice de moradores por domicílios, nas 34 comunidades, que caiu de 3,97 em 1991 para 3,58 em 2000. (CAVALLIERI, Estudos Cariocas, 2005, grifos nossos)
O estudo publicado em dezembro de 2006 na coleção Estudos Cariocas: "Favelas cariocas: comparação das áreas ocupadas - 1999/2004", constitui um marco na discussão aqui apresentada (CAVALLIERI; LOPES, Estudos Cariocas, 2006). Como indicado pelo próprio título do estudo, a variável empregada para mensurar o crescimento é, agora, a área ocupada e não o tamanho populacional (ou o número de domicílios), como ocorria nas pesquisas anteriores. 0 recurso à comparação dos perímetros das áreas faveladas é apresentado como solução, ainda que precária, para sanar a ausência de informações demográficas decorrente da não realização da Contagem da População do Rio de Janeiro em 2006. Para produzir informações sobre o crescimento das favelas, o estudo emprega, então, um dispositivo de visualização alternativo:

\begin{abstract}
A equipe técnica [do IPP] fez a comparação da área ocupada por cada uma das 750 favelas cadastradas [no Sabren], através da análise visual do melhor material disponível sobre o tema: as ortofotos digitais de 1999 e 20047. Foi possível verificar a situação de cada assentamento para se constatar se houve, e de quanto foi o crescimento ou a diminuição de suas áreas. Na linguagem urbanística, os resultados da presente pesquisa dizem respeito, exclusivamente, à chamada expansão horizontal da favela. A metodologia utilizada não permite abordar os outros dois tipos de variação: o crescimento vertical (construção de novos andares) e o adensamento do lote (construção de novas edificações num mesmo lote já ocupado). (CAVALLIERI; LOPES, Estudos Cariocas, 2006: 2, grifos nossos)
\end{abstract}

Observa-se, portanto, que o método adotado no estudo, isto é, a delimitação de áreas visando à análise das variações temporais de seus perímetros, participa diretamente da construção da visibilidade do fenômeno (do crescimento horizontal, ou extensivo) e da categorização das unidades do estudo (as favelas). Além disso, uma vez que o indicador analisado no trabalho foi a "variação das áreas ocupadas por favelas", aquelas unidades que possuíam áreas muito grandes (para os padrões analisados) mas cuja variação no período havia sido pequena (também tendo em vista a distribuição observada) não se destacaram na análise. Some-se a isso o fato de que as informações sobre as ${ }^{7} \mathrm{O}$ estudo dedica uma seção à apresentação dos aspectos técnicos associados à "capacidade de ver" das ortofotos digitais. "A primeira coleção de ortofotos digitais da cidade do Rio de Janeiro foi realizada em 1999 na escala de 1:10.000 a partir de voo na altura de 30.000 metros, com arquivos digitais que possibilitam 'visualização em tela' até 1:3.000, permitindo desta forma a delimitação digital das favelas cariocas. Mantendo o objetivo da atualização cadastral e de monitoramento da evolução urbana, foi elaborada nova coleção de ortofotos de toda a cidade em 2004, desta vez a partir de um voo aerofotogramétrico na altura de 15.000 metros que produziu fotografias na escala de 1:10.000. Embora com a mesma escala da coleção anterior (1999), foram obtidos arquivos digitais de melhor definição, permitindo 'visualizações em tela' em até 1:1.000. A diminuição na altura dos voos entre coleções de ortofotos de 1999 e 2004 (30.000 e 15.000 metros respectivamente) gerou uma melhor delimitação das favelas" (CAVALLIERI; LOPES, 2006: 3-4). 
Figura 3 - 0 crescimento das favelas e o "modo de ver" das ortofotos.

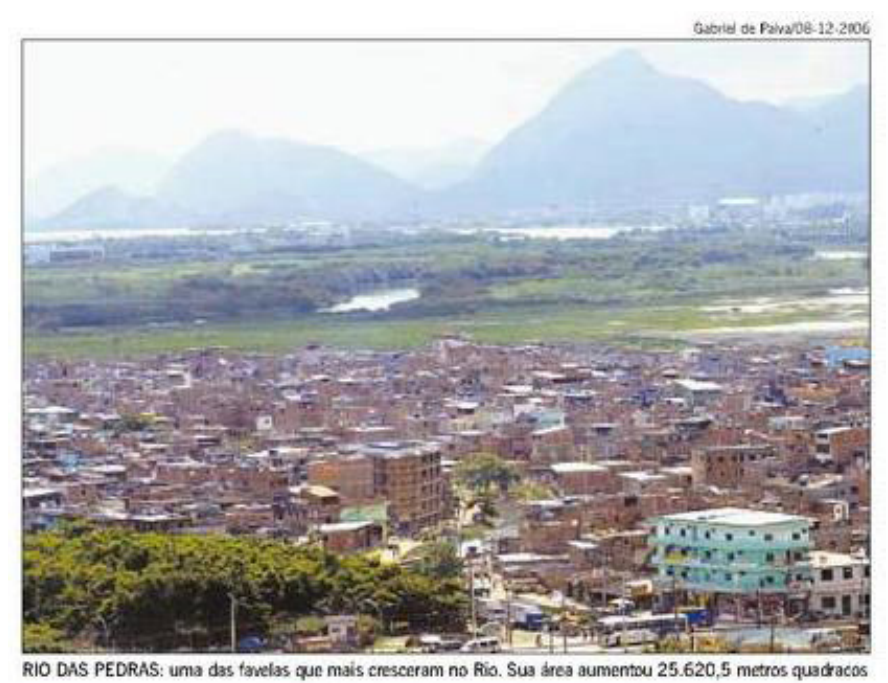

Fonte: O Globo, 16/9/2007.

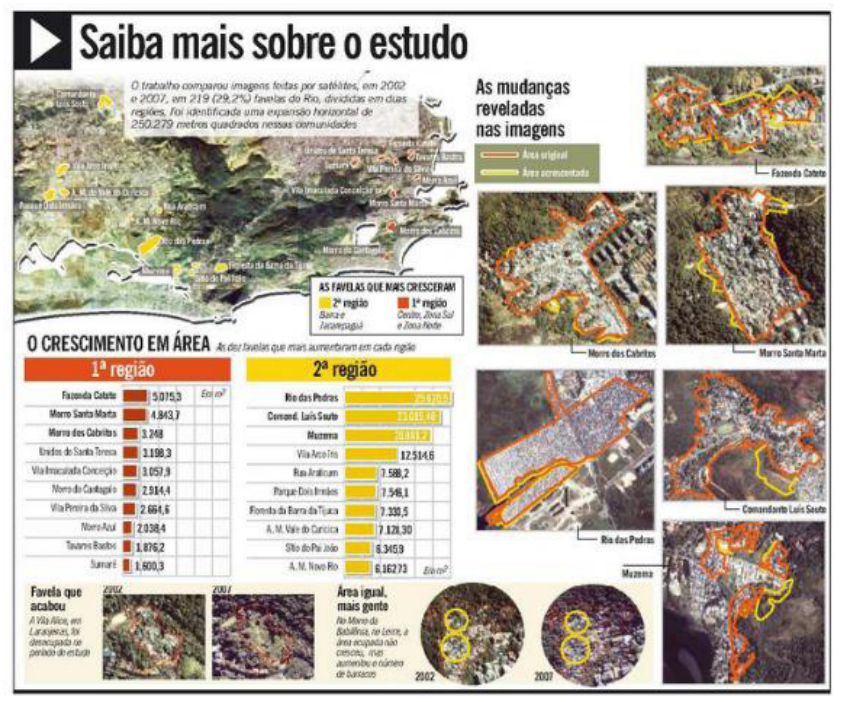

favelas da cidade foram agrupadas segundo as divisões administrativas municipais (Área de Planejamento, Região Administrativa e Bairro). Em virtude do procedimento utilizado, sobressaem no estudo, quanto às variações positivas de crescimento horizontal, a Área de Planejamento (AP) "Zona Oeste", a Região Administrativa (RA) "Guaratiba" e o Bairro de Guaratiba, embora, segundo o próprio estudo, essas áreas apresentassem a menor proporção de área ocupada por favelas.

Esta forma nova de "ver" o crescimento urbano ganha destaque em matéria do jornal 0 Globo, publicada em setembro de 2007: "Rio Ganha 4,5 morros Santa Marta de áreas faveladas em 5 anos". Integram a matéria uma vista aérea da favela Rio das Pedras e um infográfico subintitulado "as mudanças reveladas nas imagens" (Figura 3).

Note-se que a matéria lança mão de outro recurso utilizado anteriormente, qual seja, recompor o crescimento total das favelas (neste caso, o crescimento horizontal) em uma única unidade espacial. Contudo, o que se ganha não é mais o equivalente à população referente à unidade espacial de comparação (como Petrópolis e Nova Friburgo), mas sim o equivalente à sua área (neste caso, a unidade de comparação é o Santa Marta, favela que jogava um importante papel na redefinição de políticas voltadas para as favelas):

\begin{abstract}
Estudo encomendado pelo Sistema Firjan (Federação da Indústrias do Estado do Rio) quantifica o que se observa sem a ajuda de equipamentos: a expansão das favelas não é só vertical. Imagens de satélite, feitas em 2002 e 2007 , em $29,2 \%$ das favelas cadastradas oficialmente pela prefeitura, revelam um crescimento horizontal, em cinco anos, nestas comunidades, de 250.358 metros quadrados, o equivalente a mais de quatro vezes e meia a área ocupada pelo Morro Santa Marta, em Botafogo (ele tem 54.168 metros quadrados). - Para se ter uma ideia do futuro, se nada for feito e as favelas continuarem se expandindo no mesmo ritmo, em 2015 teremos no Rio um novo Borel (o morro tem 392.274 metros quadrados), avalia Luciana Costa Marques de Sá, diretora de Desenvolvimento Econômico da Firjan. (O Globo, 16 de setembro de 2007, grifos nossos)
\end{abstract}

Ainda de acordo com a reportagem, o "monitoramento das favelas" estava previsto no Mapa do Desenvolvimento do Estado do Rio de Janeiro, divulgado pela Firjan em 2006, que sugeria, entre as ações propostas, o controle das sub-habitações em favelas, áreas de risco e de preservação ambiental. Na mesma matéria, o ainda presidente do IPP, Sérgio Besserman, afirma que o estudo da Firjan confirma o trabalho anterior divulgado pelo IPP e que, em 2008, o Instituto pretendia encomendar novas imagens para dar sequência ao seu próprio levantamento.

É interessante notar como o próprio debate intermediado pelo jornal é reconstituído em termos da 
questão da visibilidade. Já no lide (no jargão jornalístico, o parágrafo que "guia" a matéria), reproduzido na citação acima, afırma-se que é possível "observar sem ajuda de equipamentos", a olho nu, aquilo que é "visto" pela pesquisa encomendada pela Firjan, ou seja, aquilo que, de acordo com o texto do infográfico, as "imagens revelam": o crescimento das favelas. Já no final da matéria há uma seção dedicada à entrevista com Luiz Cesar Queiroz Ribeiro, coordenador do Observatório das Metrópoles, do Instituto de Pesquisa e Planejamento Urbano e Regional (IPPUR/UFRJ), o qual afirma: "não basta olhar só para a favela, tendo em vista que elas são consequência, e não causa" (O Globo, 16 de setembro de 2007, grifos nossos).

O tipo de visualização associado ao crescimento horizontal das favelas é novamente empregado em outra reportagem do jornal 0 Globo do mesmo ano para descrever "a pressão da favela sobre a floresta" (O Globo, 21 de dezembro de 2007). No momento em que a matéria foi publicada, o governo municipal (sob o comando do então prefeito Cesar Maia) cogitava enviar à Câmara Municipal um projeto de lei que declararia a favela Chácara do Céu - situada no morro Dois Irmãos, na Zona Sul da cidade - Área de Especial Interesse

Figura 4 - 0 crescimento, seus limites e suas interfaces.

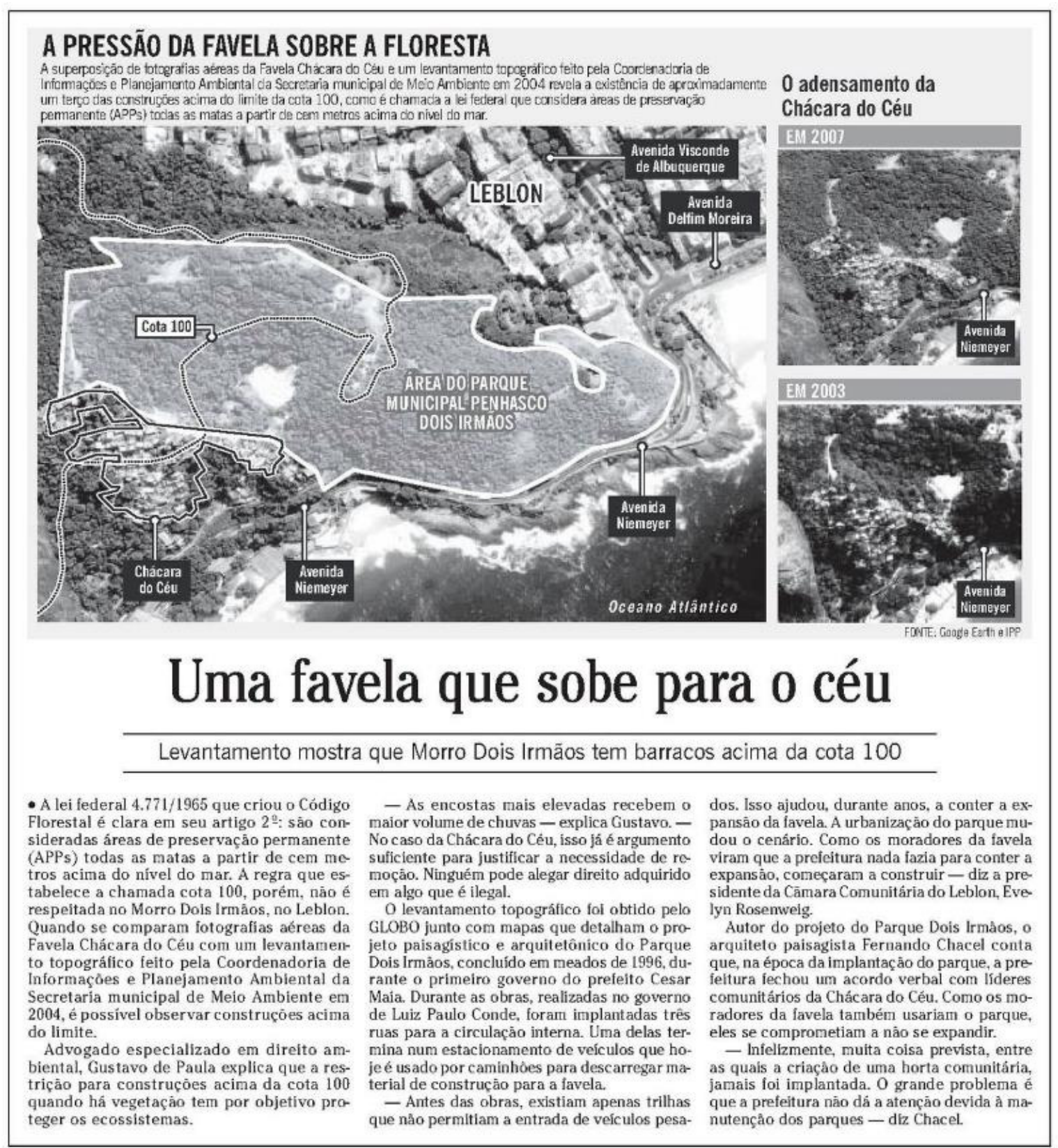

Fonte: O Globo, 21/12/2007. 
Social (AEIS). Concomitantemente, o Ministério Público do Rio de Janeiro (MPRJ), por intermédio da Promotoria de Meio Ambiente e Patrimônio Histórico, havia anunciado que processaria o município por não impedir a favelização do Morro Dois Irmãos. No contexto desta disputa, a reportagem apresenta uma composição de imagens (Figura 4) acompanhadas da seguinte legenda:

\begin{abstract}
A superposição de fotografias aéreas da Favela Chácara do Céu e um levantamento topográfico feito pela Coordenadoria de Informações e Planejamento Ambiental da Secretaria Municipal de Meio Ambiente em 2004 revela a existência de aproximadamente um terço das construções acima da cota 100 , como é chamada a lei federal que considera áreas de preservação permanente (APPs) todas as matas a partir de cem metros acima do nível do mar. (O Globo, 21 de dezembro de 2007, grifos nossos)
\end{abstract}

Como se pode observar na figura acima, a imagem principal inscreve sobre uma base extraída do Google Earth a delimitação da favela Chácara do Céu (conforme o IPP), a curva de nível correspondente à cota de 100 metros e a área do Parque Natural Municipal Penhasco Dois Irmãos. A integração, pela imagem, de perímetros correspondentes a diferentes unidades espaciais e da linha que demarca a cota de 100 metros torna visível a interface entre estes elementos e sua eventual sobreposição. Embora já mencionado textualmente em matérias anteriores, o problema associado à expansão do perímetro das favelas cariocas "sobre" as "áreas de preservação" é aqui "imaginado" no terreno, por meio de um dispositivo gráfico, tornando-o passível de visualização e mensuração. Como vimos anteriormente, o mesmo problema da interface entre "favelas" e "áreas verdes" também vinha sendo tematizado, desde o início dos anos 2000, no longo debate público acerca da implantação do projeto dos "ecolimites".

A partir de meados dos anos 2000, o crescimento horizontal passou a ser empregado como indicador para a avaliação das políticas públicas municipais, como se pode constatar no trabalho publicado na coleção Estudos Cariocas, em maio de 2009: "O efeito da presença governamental sobre a expansão horizontal das favelas do Rio de Janeiro: os Pouso's e o Programa FavelaBairro". A hipótese central, confirmada pelo estudo, seria de que as favelas beneficiadas pelo Programa Favela-Bairro e depois assistidas pelos Pouso's (Posto de Orientação Urbanística e Social) tiveram menor crescimento de sua área de abrangência do que suas equivalentes não incluídas (VIAL; CAVALLIERI, Estudos Cariocas, 2009). O crescimento foi medido, novamente, em termos de variação da área ocupada pelas favelas entre os anos de 1999 e $2008^{8}$.

Durante as duas gestões do prefeito Eduardo Paes (2009-2012e2013-2016)amplia-seainstitucionalização desse novo regime de visibilidade. Em janeiro de 2011, o executivo municipal publica o Decreto n. 33.371, que "dispõe sobre levantamento aerofotogramétrico no município e dá outras providências". Os "considerandos" do decreto enumeram as seguintes razões que motivaram o ato normativo: "a dinâmica do desenvolvimento urbano da cidade que gera mudanças muito rápidas na forma de ocupação e uso do solo urbano" e "a necessidade de monitorar a existência e a expansão dos assentamentos precários com características de favela para informar aos órgãos executores das políticas públicas municipais a eles dirigidos". O texto do decreto opera, como é de se esperar, uma tradução normativa dos elementos que compõem o novo regime de visibilidade do problema do crescimento urbano:

Art. $1^{\circ}$. O Instituto Municipal de Urbanismo Pereira Passos-IPP realizará, a cada ano, o levantamento aerofotogramétrico do Município, cujas imagens digitais permitam, por meio da fotointerpretação, identificar mudanças no uso do solo, decorrentes da dinâmica urbana.

Parágrafo único. Com base nesse levantamento, o IPP procederá, anualmente, à identificação e demarcação dos limites das áreas com características de favela.

Art. $2^{\circ}$. As áreas citadas no artigo anterior serão identificadas com base nas seguintes características principais, que as diferenciam das áreas urbanizadas: I - precariedade da organização espacial com lotes de tamanho e forma irregular, normalmente menores do que os das áreas formais, caracterizando maior adensamento na ocupação do solo;

II - especificidade do sistema viário interno, composto por vias estreitas, de alinhamento e tamanho irregulares, nem sempre pavimentadas ou carroçáveis, frequentemente sem calçadas para pedestres;

III - edificações, em sua maioria, bem menores que as das áreas formais, sem telhados, com lajes como cobertura final e com paredes externas sem revestimento".

Art. $5^{\circ}$ Caberá ainda ao IPP medir, anualmente, as áreas ocupadas pelas favelas cadastradas no Sabren, comparando-as com as dos anos anteriores, e dar publicidade aos órgãos municipais, que trabalham com o tema, sobre os resultados dessas medições. (Rio de Janeiro, 2011, grifos nossos)

O artigo primeiro do decreto estabelece, de saída, o ponto de vista, ou seja, "quem olha", "de onde olha" e "como olha" (por meio de qual instrumento). Indica

\footnotetext{
Em junho de 2009, o referido estudo foi objeto de matéria no jornal o Globo intitulada: "Favelas, um problema em expansão na cidade" (O Globo, 29 de junho de 2009)
} 
ainda o que deve ser visto: as "mudanças no uso do solo decorrentes da dinâmica urbana", traduzindo o problema do crescimento nos termos consagrados pela legislação urbanística. 0 parágrafo único do artigo primeiro indica um dos resultados esperados da aplicação da norma, qual seja, a identificação e a delimitação das áreas cujo tipo de uso do solo apresente "características" de favela, distinguindo-as de outras classes de área de uso "urbano".

Em função do dispositivo de visualização escolhido, as "características principais" das favelas são, por óbvio, aquelas passíveis de identificação a partir da fotointerpretação, e dizem respeito aos aspectos geométricos (tamanho e forma) de alguns de seus elementos constitutivos (lotes, sistema viário e edificações) em função daquilo que os diferencia das "áreas formais". Destaca-se ainda a finalidade cognitiva da norma, qual seja, mensurar e comparar, no tempo (anualmente), as variações de área das unidades espaciais observadas, compartilhando esse conhecimento (dando-Ihe "publicidade") na rede de órgãos da esfera municipal que participam diretamente da gestão da dinâmica urbana da cidade? .

Figura 5 - Descrever o crescimento urbano: pontos de vista e composições.

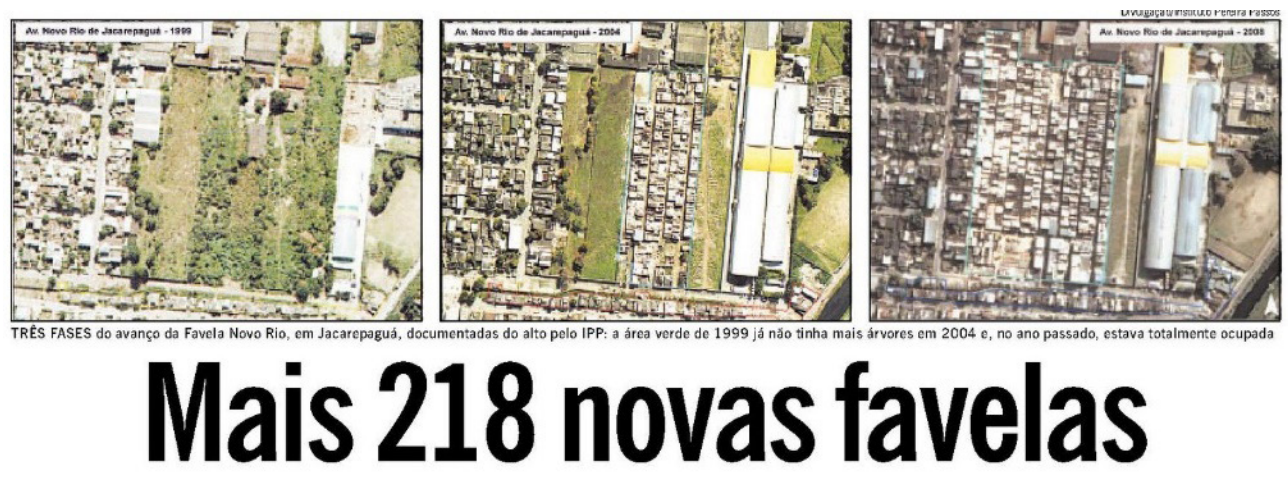

Ao contrário do que se afirmava, expansão horizontal foi de 7\% entre 99 e 2008

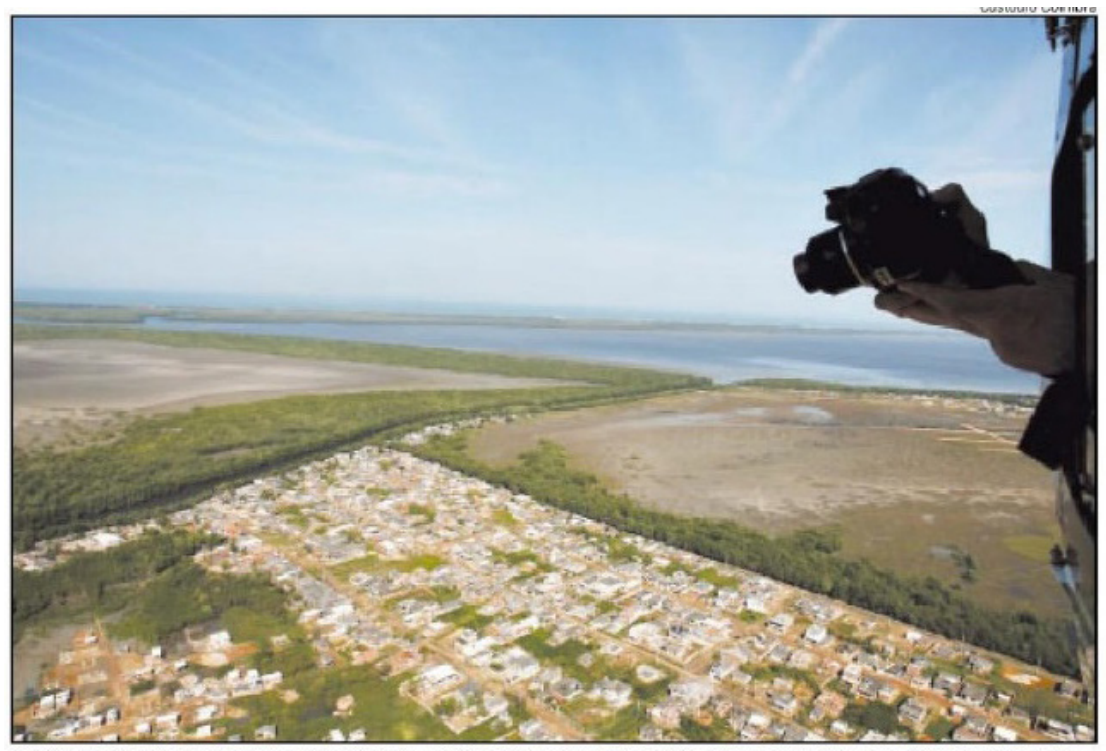

A FAVELA QUE mais cresceu, a Rio Piraquê, em Guaratiba: aumento de 81 por cento da área nos últimos nove anos

Fonte: 0 Globo, 01/10/2009. 
O que sobressai desta discussão é que a progressiva redefinição do problema do crescimento urbano na Cidade do Rio de Janeiro, ao longo dos anos 2000, esteve diretamente relacionada à construção de uma nova forma de descrever este problema, ou seja, de produzir imagens para pensar (GOMES, 2017) sobre ele, para conhecê-lo. Vejamos, na figura abaixo (Figura 5), alguns dos aspectos desta descrição na matéria publicada no jornal O Globo, em outubro de 2009, intitulada: "Mais 218 favelas".

A legenda da sequência de imagens no topo da página diz o seguinte: "Três fases do avanço da favela Novo Rio, em Jacarepaguá, documentadas do alto pelo IPP, a área verde de 1999 já não tinha mais árvores em 2004 e, no ano passado [2008], estava totalmente ocupada" (O Globo, 1 de outubro de 2009, grifos nossos). Notase, em primeiro lugar, a estabilização de um ponto de vista ${ }^{10}$, "do alto", aéreo, ortogonal, que corresponde ao olhar de um ator privilegiado, neste caso, o IPP, obtido a partir de um instrumento de sensoriamento remoto. A descrição proposta pela matéria apresenta ainda, na imagem inferior, um segundo ponto de vista, do tipo "voo de pássaro", um olhar topográfico utilizado para tornar visível a volumetria do terreno.

Nesta imagem, o instrumento de sensoriamento remoto, uma câmera fotográfica, está visível. A mão que empunha a câmera, também visível, associada ao crédito da imagem, permite associar este ponto de vista ao olhar de um personagem específico (com estatuto semelhante àquele atribuído ao Instituto Pereira Passos na imagem superior), o fotojornalista Custódio Coimbra. Os enquadramentos, por sua vez, estabelecem os limites da visualização e, ao mesmo tempo, delimitam composições, ou seja, os jogos de posições relativas de coisas e de formas distribuídas em um mesmo plano (GOMES, 2013: 22). As "coisas" ou "formas" relevantes são designadas na legenda da imagem superior: a "favela" e a "área verde". Estas são, portanto, as unidades espaciais colocadas em relação em cada uma das composições ${ }^{11}$.

0 recurso à foto-sequência permite descrever a temporalidade do fenômeno do crescimento, caraterizada pela progressiva substituição de uma forma pela outra ou, como descrito na legenda, pela supressão da vegetação e pela "ocupação" da área verde. Em resumo, poderíamos dizer que esta matéria - assim como outros textos e imagens anteriormente analisados -, ao mesmo tempo, testemunha e participa da emergência de um novo regime de visibilidade (GOMES, 2013) associado ao problema do crescimento urbano no Rio de Janeiro.

\section{De olho no "lado de lá"}

Em 2016, o Instituto Estadual do Ambiente (Inea) lançou o projeto "Olho no Verde". O jornal O Globo assim o descreveu, em matéria publicada em dezembro de 2017:

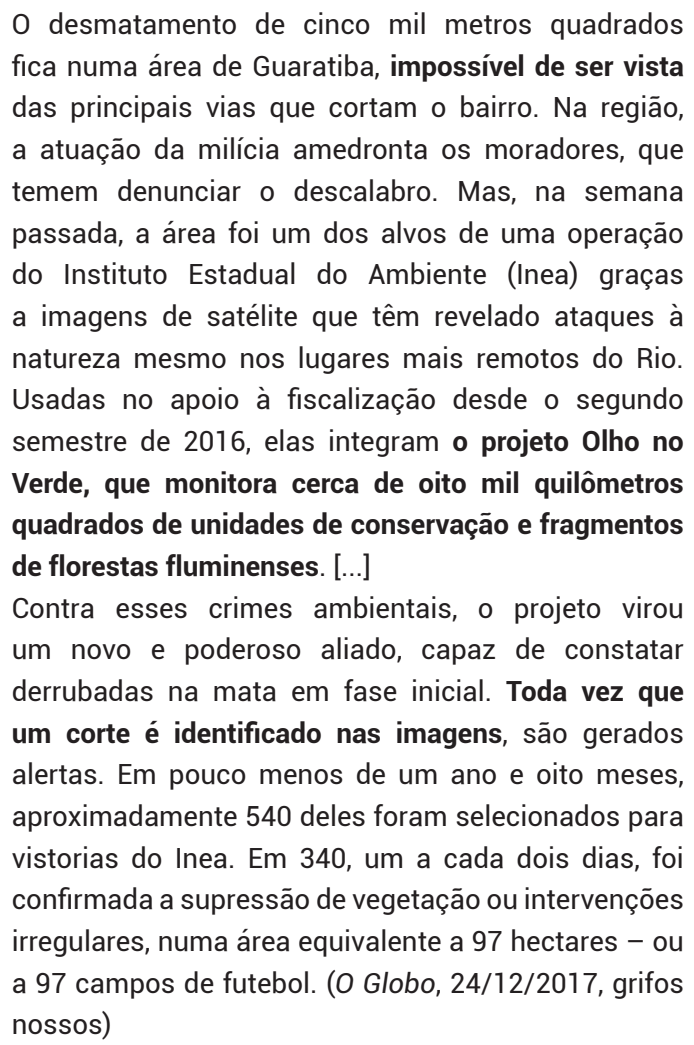

O método de deteç̧ão empregado para monitorar as alterações na cobertura vegetal, ou melhor, a supressão da vegetação, foi assim descrito pelo subsecretário estadual do Ambiente à reportagem:

\begin{abstract}
O Olho no Verde funciona com base em varreduras feitas semanalmente por quatro satélites de uma empresa americana, que são enviadas para o Laboratório Espaço de Sensoriamento Remoto e Estudos Ambientais, no Departamento de Geografia da UFRJ. As imagens de alta resolução, que permitem que o corte de uma única árvore possa ser observado, são comparadas regularmente. Toda vez que uma diferença no padrão de cor é constatada, são criados os alertas, posteriormente checados em campo pelos fiscais do estado. (O Globo, 24/12/2017)
\end{abstract}

A exposição do projeto e do método empregado, acompanhada das imagens que compõem a reportagem (Figura 6), nos permitem acessar o mesmo regime de visibilidade acima descrito, porém na perspectiva de um instrumento de política pública que emana de outra 
Figura 6 - Pontos de vista para descrever a supressão da floresta.

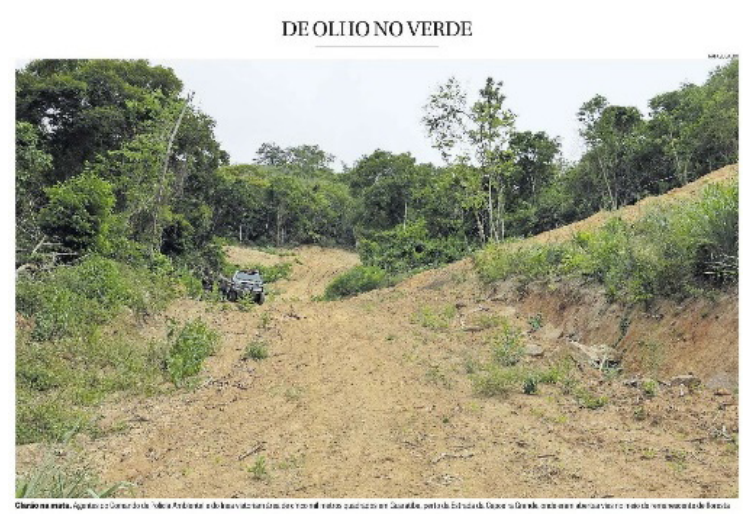

Big Brother da natureza

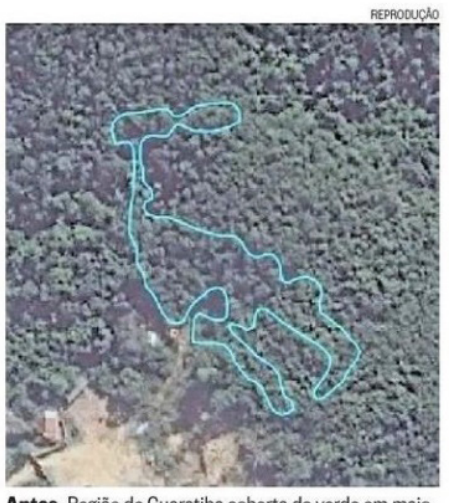

Antes. Região de Guaratiba coberta de verde em maio

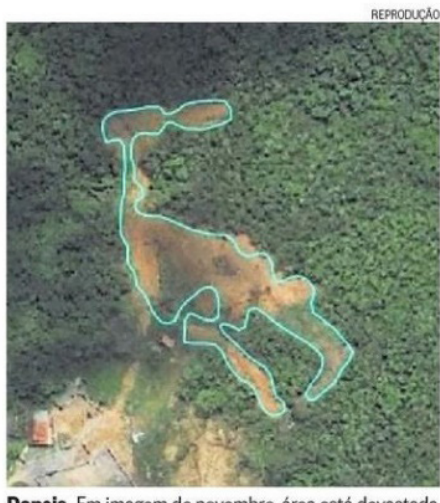

Depois. Em imagem de novembro, área está devastada

Monitoramento de florestas por satélite flagra, em média, um desmatamento a cada dois dias

Fonte: O Globo, 24/12/2017.

esfera de governo, neste caso estadual. O ponto de vista aéreo, dos satélites, é associado ao olhar do fiscal de campo e, na matéria, ao olhar do jornalista que procura "capturar" o "instante decisivo" que corresponde à vistoria dos agentes da Polícia Ambiental e do Inea em uma das vias recém-abertas "no meio do remanescente de floresta" no bairro de Guaratiba.

Além disso, o mesmo recurso à foto-sequência é empregado para descrever o fenômeno, como uma alteração, no tempo, do "atributo" que qualifica a área delimitada. Afirma a legenda: "Antes. Região de Guaratiba coberta de verde em maio. Depois. Em imagem de novembro, área está devastada" ( $O$ Globo, 24/12/2017). Neste caso, o limite da área, inscrito na imagem, constitui, efetivamente, um dispositivo de visualização da supressão da vegetação. Trata-se do mesmo problema do crescimento horizontal, descrito agora da perspectiva inversa, em espelho, ou seja, do uso suprimido.

\section{Considerações finais}

A redefinição do problema público do crescimento urbano no Rio de Janeiro passa, necessariamente, por uma mudança cognitiva, conforme propõe Cefai (2018Esta pode ser observada em termos da produção normativa orientada para a gestão deste problema público $^{12}$, bem como na transformação do regime de visibilidade a ele associado. Esta transformação corresponde a um novo modo de imaginar, conceber e dar publicidade ao crescimento urbano.

0 momento anterior a esta redefinição compreendia o crescimento urbano em termos do crescimento populacional nas favelas, como visto nos trabalhos do Instituto Pereira Passos e nas notícias do jornal O Globo. A política urbana carioca considera o crescimento ao menos desde 1990, mas os instrumentos de regulação de uso e ocupação do solo se prestavam à sua orientação. A partir dos anos 2000, e bastante claramente a partir do Plano Diretor de 2011, é que o crescimento passa a ser visto a partir da lógica do uso do solo, onde o que interessa é a variação do perímetro de determinadas "classes de área" ou entidades espaciais, sejam aquelas ligadas ao "urbano", particularmente as favelas, sejam aquelas ligadas ao seu "oposto", as categorias associadas à natureza.

Os novos pontos de vista associados a novas técnicas de visualização, como as ortofotos e imagens de satélite, dão a ver um tipo de composição que ressalta não mais o crescimento demográfico das favelas, mas sim o seu crescimento horizontal, ou seja, de suas áreas. Neste sentido, a redefinição dos atributos mensurados nas favelas redefine a própria categoria espacial "favela", entidade unificada espacialmente pelos limites agora inscritos nos mapas e comparados periodicamente. É a partir deste novo modo de ver o crescimento, notadamente das favelas, que o crescimento urbano passa a ser um problema que demanda, inclusive, instrumentos de delimitação física.

Ver como uma cidade, no sentido proposto por Valverde, implica um governo dos usos, mas que se dá, fundamentalmente, através da classificação de áreas. Os 
limites entre essas áreas jogam um papel fundamental na ordenação do espaço urbano e destacam-se na redefinição do problema do crescimento urbano no Rio de Janeiro. Estes limites atuam não como elementos de separação das áreas em justaposição, mas como descontinuidades que produzem interfaces, ou seja, relações entre conjuntos espaciais distintos. No caso do problema público do crescimento urbano no Rio de Janeiro, o novo regime de visibilidade coloca em destaque as "zonas de contato", sobretudo entre favelas e áreas de proteção ambiental, ou, de uma maneira mais geral, entre a "cidade" e a "natureza", explicitando a necessidade de políticas urbanas que atentem para o caráter descontínuo da cidade.

\section{Referências}

BARNIER, Véronique; TUCOULET, Carole. (1999). Avant-propos. In: Ville et environnement: de l'écologie urbaine à la ville durable. Paris: La Documentation Française, n. 829, p. 3-5.

BARRACOS em expansão. (2004). O Globo, Rio de Janeiro, 16 de maio.

BENGSTON, D.; YOUN, Y-C. (2006). Urban Containment Policies and the Protection of Natural Areas: The Case of Seoul's Greenbelt. Ecology and Society, v. 11, n. 3. [Online]. Disponível em: <http://www.ecologyandsociety.org/vol11/ iss $1 /$ art3/>.

BENGSTON, D.; FLETCHER, J.; NELSON, K. (2004). Public policies for managing urban growth and protecting open space: policy instruments and lessons learned in the United States. Landscape and Urban Planning, n. 69, p. 271-286.

BESSERMAN, Sérgio; CAVALLIERI, Fernando. (2004). Nota técnica sobre o crescimento da população favelada entre 1991 e 2000 na cidade do Rio de Janeiro. Coleção Estudos Cariocas, n. 20040601, IPP/Prefeitura da Cidade do Rio de Janeiro, junho, $5 p$.

BIG Brother da natureza. (2017). O Globo, Rio de Janeiro, 24 de dezembro.

BLOMLEY, Nicholas; DELANEY, David; FORD, Richard (eds.). (2001). The Legal Geographies Reader. Oxford: Blackwell Publishers.

BLOMLEY, Nicholas. (2016). Land use, planning, and the "difficult character of property. Planning Theory and Practice, v. 18, n. 3, p. 351-364.

BRAVERMAN. Irus; BLOMLEY, Nicholas; DELANEY, David; KEDAR (eds.). (2014). The expanding spaces of law: a timely legal Geography. Stanford: Stanford University Press.

CAPEL, Horacio. (2002). La Morfología de las ciudades: I. Sociedad, cultura y paisaje urbano. Barcelona: Ediciones de Serbal.

COSTA, Heloisa. (1999). Desenvolvimento urbano sustentável: uma contradição de termos? Revista Brasileira de 
Estudos Urbanos e Regionais, n. 2, p. 56-71.

CAVALLIERI, Fernando. (2005). O momento 2000 do programa Favela-Bairro: avaliação com base nos censos 1991 e 2000. Coleção Estudos Cariocas, n. 20050101, IPP/Prefeitura da Cidade do Rio de Janeiro, janeiro, 8p.

CAVALLIERI, Fernando; LOPES, Gustavo. (2006). Favelas cariocas: comparação das áreas ocupadas - $1999 / 2004$. Coleção Estudos Cariocas. Rio de Janeiro.

CAVALLIERI, Fernando; VIAL, Adriana; LOPES, Gustavo Peres. (2007). Diferenciais Intraurbanos no Rio de Janeiro: contribuição ao cumprimento da meta 11 do milênio. Coleção Estudos Cariocas, n. 20070302, IPP/Prefeitura da Cidade do Rio de Janeiro e Maurício de Almeida Abreu (consultor), março, 15p.

CESAR Joga a Toalha. (2007). O Globo, Rio de Janeiro, 21 de dezembro.

CEZAR, Paulo Bastos. (2002). Evolução da população de favelas na cidade do Rio de Janeiro: uma reflexão sobre os dados mais recentes. Coleção Estudos Cariocas, n. 20020201, IPP/Prefeitura da Cidade do Rio de Janeiro, fevereiro, $13 p$.

CEFAI, Daniel. (2018). Público, Socialização e Politização: reler John Dewey na companhia de George Herbert Mead. In: CORRÊA, D. et al. (org.). Crítica e pragmatismo na Sociologia: diálogos entre Brasil e França. São Paulo: Annablume Editora, p. 57-88.

CIDADE incha pelas favelas: estudo revela que Rio voltou a crescer e ganhou uma Petrópolis entre 96 e 2000. (2001). O Globo, Rio de Janeiro, 29 de maio.

EXPANSÃO fora do mapa : há dois anos, prefeitura não faz fotos aéreas para monitorar crescimento de favelas. (2015). O Globo, Rio de Janeiro, 15 de maio.

FRANKHAUSER, Pierre. (1994). La fractalité des structures urbaines. Economica: Paris.

GEORGE, Pierre. (1983). Geografia Urbana. São Paulo: Difel [1961].

GOMES, Paulo Cesar da Costa. (2013). O Lugar do Olhar: elementos para uma geografia da visibilidade. Rio de Janeiro: Bertrand Brasil.

GOMES, Paulo Cesar da Costa. (2017). Quadros Geográficos: uma forma de ver, uma forma de pensar. Rio de Janeiro: Bertrand Brasil.

GONÇALVES, Rafael. (2013). Favelas do Rio de Janeiro: História e Direito. Rio de Janeiro: Pallas/PUC-Rio.

HALL, Peter. (2013). Cidades do amanhã: uma história intelectual do planejamento e do projeto urbanos no século XX. São Paulo: Perspectiva.

MACHADO, Ana Brasil. (2017). Os ecolimites no Rio de Janeiro: política e gestão de interfaces urbanas. Rio de Janeiro: Novas Edições Acadêmicas.

MACHADO, Ana Brasil. (2018a). Da política dos espaços públicos: esfera pública e política urbana no caso do ecolimite da Rocinha, Geografares, julho-setembro, 147-161.

MACHADO, Ana Brasil. (2018b). Os limites do Rio: natureza e expansão urbana na Cidade do Rio de Janeiro (1990 a 2013). Rio de Janeiro, UFRJ, Tese de Doutorado defendida no Programa de Pós-Graduação em Geografia.

MAIS 218 Favelas. (2009). O Globo, Rio de Janeiro, 1 de outubro.

MURDOCH, Jonathan. (2006). Post-structuralist geography. Londres: SAGE Publications.

PEDROSO, Isabella. (2009). O Estado e os Muros: um estudo sobre as políticas destinadas às favelas cariocas através da mídia impressa. Rio de Janeiro, UERJ, Monografia defendida no Programa de Pós-graduação em Ciências Sociais, Curso de Especialização em Sociologia Urbana.

PENDALL, Rolf; MARTIN, Jonathan; FULTON, William. (2002). Holding the Line: urban containment in the United States. 
Manuscript. Department of City and Regional Planning, Cornel University.

RIO DE JANEIRO. (2011). Decreto n. 33.371. Dispõe sobre levantamento aerofotogramétrico no município e dá outras providências.

RIO Ganha 4,5 morros Santa Marta de áreas faveladas em 5 anos. (2007). O Globo, Rio de Janeiro, 16 de setembro.

ROBIC, Marie-Claire. (2003). La ville, objet ou probleme? La geographie urbaine en France (1890-1960), Sociétés contemporaines, n. 49-50, p. 107-138.

ROBIC, Marie-Claire. (2006). A crise dos anos 30 e a emergência de novos temas na geografia. In: SALGUEIRO, Heliana Angotti (org.). Pierre Mombeig e a geografia humana brasileira: a dinâmica da transformação. Bauru/SP. Edusc.

ROSALES, Verónica; SANCHÉZ, Pedro. (2011). Sustentabilidad urbana: planteamientos teóricos y conceptuales. Quivera, vol. 13, n. 1, p. 180-196.

VALVERDE, Mariana. (2011). Seeing Like a City: The Dialectic of Modern and Premodern Ways of Seeing in Urban Governance. Law and Society Review, 45 (2), p. 277-310.

VALVERDE, Mariana. (2005). Taking "land use" seriously: toward an ontology of municipal law. Law Text Culture, 9, p. 34-39.

VIAL, Adriana; CAVALLIERI, Fernando. (2009). O efeito da presença governamental sobre a expansão horizontal das favelas do Rio de Janeiro: os Pouso's e o Programa Favela-Bairro. Coleção Estudos Cariocas, n. 20090501, IPP/ Prefeitura da Cidade do Rio de Janeiro, maio.

VILLAMIZAR-DUARTE, Natalia e SÁNCHEZ, Jeny. (2012). Bordes urbanos: una pregunta desde el crecimiento de las ciudades hacia la concepción de una categoría para el análisis y la proyectación de territorios urbanos. Seminario Bordes Urbanos: Procesos Territoriales Colombia, Chile, Gran Bretaña, India, China, España. 